\title{
Magnetization transfer imaging of the pituitary gland
}

\author{
Maria I. Argyropoulou ${ }^{1}$, Dimitrios Nikiforos Kiortsis ${ }^{2}$ \\ ${ }^{1}$ Department of Radiology, Medical School University of Ioannina, ${ }^{2}$ Department of Physiology, Medical School \\ University of Ioannina, Ioannina, Greece
}

\begin{abstract}
Magnetization transfer (MT) techniques provide tissue contrast which depends mainly on the concentration of macromolecules. The magnetization transfer phenomenon is determined by the restricted macromolecular protons and is quantified by the magnetization transfer ratio (MTR). Since many macromolecular structures are implicated in the secretory activity of the pituitary gland, this imaging technique has recently been used for the study of the normal adenohypophysis and the pre-operative and post-operative evaluation of pituitary adenomas. Significant changes of the MTR with age occur in normal subjects. In patients with hyperprolactinemia, the MTR of prolactin-secreting tumors is higher and that of the non secreting adenomas is lower compared to the MTR values of the normal pituitary gland of age and sex matched controls. In some patients operated on for growth hormone adenomas, although classic MR images were negative for residual tumor, increased MTR values were highly suggestive of persistence of adenoma tissue, in agreement with biochemical findings of persisting secretory activity. These data suggest that MT techniques might be an additional useful tool in the assessment of pituitary gland disorders.
\end{abstract}

Key words: Magnetization transfer, pituitary gland

\section{INTRODUCTION}

Magnetic Resonance Imaging (MRI), using T2 and T1 (plain and contrast enhanced) weighted sequences, is the modality of choice for imaging of the hypothalamo-pituitary region ${ }^{1}$. The signal characteristics of the normal pituitary gland and its size as a function of age are well established by MR studies. Detectability of pituitary gland lesions is based on differences in

Address correspondence and requests for reprints to: Maria I Argyropoulou, Assoc. Prof. of Radiology, Medical School, University of Ioannina, 45110 Ioannina, Greece, Tel.: +3026510 97733, +3026510 97862, e-mail:margyrop@cc.uoi.gr

Received 05-02-03, Revised 11-03-03, Accepted 28-03-03 signal characteristics between the normal pituitary tissue and the lesion. Pituitary adenomas are well depicted in T1 and T2 weighted images; nevertheless, the secretory activity of these lesions cannot be evaluated using these classic MR sequences. For this reason, classic MR sequences cannot differentiate secreting from non-secreting adenomas, which is crucial especially in hyperprolactinemias ${ }^{2-4}$. Another important limitation of the classic MR protocols is that, in some cases after surgery for secretory adenomas, the MRI does not depict residual tumor although endocrine tests suggest continuing secretory activity.

Magnetization transfer imaging has recently been used for the study of the normal adenohypophysis and the pre-operative and post-operative evaluation of pituitary adenomas ${ }^{5-7}$. Magnetization transfer (MT) 
techniques offer a different image contrast than T1 and T2 imaging. In the classic MR sequences, tissue contrast depends mainly on the presence of free water protons, while in MT images tissue signal is determined by the restricted macromolecular protons ${ }^{8-18}$. The latter, due to their very short T2 $(<200$ microsecond), are "invisible" on standard MR sequences ${ }^{15}$. However, there is a continuous exchange of energy between the pool of free water protons and that of the macromolecular protons. Therefore, saturation of the macromolecular protons accomplished by specific pre-pulses (on- or off-resonance) can be transferred to the pool of free water protons and influence image contrast ${ }^{9}$. MR sequences free from $\mathrm{T} 1$ and $\mathrm{T} 2$ contrast, namely proton density images, are the most suitable for magnetization transfer imaging. Tissues containing macromolecules transfer magnetization more efficiently and appear with low signal on MT images (Figure 1). In contrast, tissues poor in macromolecular structures exhibit higher signal on MT images. The magnetization transfer phenomenon can be quantified using two interleaved proton density sequences, one without and the other with the magnetization transfer pre-pulse (Figure 1). The magnetization transfer ratio (MTR) is defined as: $M T R=(1-\mathrm{Ms} /$ Mo)x $100 \%$, where Ms refers to the signal intensity from the image acquired with the application of the MT prepulse and Mo the signal intensity from the image without the MT prepulse. The MTR of a tissue is determined by the concentration of macromolecules and the efficacy of interaction between the restricted and the free pool of protons ${ }^{15,16}$.

Peptide hormones produced by the pituitary gland, although macromolecules (molecular weight of 20000$30000 \mathrm{Da}$ ), do not transfer the magnetization efficient$\mathrm{ly}^{17,19}$. However, the synthesis and secretion of hormones is a process implicating intracellular membranous structures consisting of macromolecules. The rough endoplasmic reticulum (RER) is the largest membrane in a eukaryotic cell and consists of a network of interconnected closed membrane vesicles ${ }^{20}$. The RER synthesizes a number of membrane and organelle proteins and virtually all peptides secreted from the cell ${ }^{20,21}$. It has been demonstrated by electron microscopy that an increase in the peptide synthetic activity of a cell is associated with an increase of the RER ${ }^{22,23}$. Therefore, an increase in secretory activity of the adenohypophysis is characterized by a more prominent RER. Changes in this membranous structure, consisting of macromolecules, may influence the MTR of the pituitary gland.

\section{MAGNETIZATION TRANSFER IMAGING OF THE NORMAL PITUITARY GLAND}

Since the biosynthetic activity of the adenohypophyseal cells changes with age, it might influence the degree to which the gland transfers magnetization. Using a 3D gradient echo sequence (32/8/8 repetition time/echo time/flip angle), we have previously investigated the MTR of the normal pituitary gland in 117 subjects (56 males and 61 females) aged 7 months to 77 years $^{5}$. Up to puberty there was an increase of the MTR in both sexes. After the age of 20 years a progressive decrease occurred, probably reflecting the declining pituitary secretory activity ${ }^{24}$. However, women aged 50-59 years exhibited an increase of MTR. This was probably due to the significant increase of $\mathrm{LH}$ and $\mathrm{FSH}$, as the secretion of these hormones is no longer restrained by the gonadal hormones. No parallel increase was observed in men aged 50-59 years, probably because ageing in men is not generally associated with a dramatic decrease in gonadal function $^{25}$. This study provided normal values of the MTR of the pituitary gland. Moreover, changes of MTR with age may suggest that this method might be an additional useful tool for the assessment of the pituitary secretory activity.

\section{MAGNETIZATION TRANSFER IMAGING OF ADENOMAS}

A frequent cause of hyperprolactinemia is pituitary adenomas. Prolactinomas may cause substantial elevations in plasma prolactin levels. However, in some cases the cause of hyperprolactinemia is not a prolactin-secreting adenoma but a non-secreting adenoma of the pituitary gland. The differential diagnosis is important because treatment might be different in these two types of pituitary adenomas. In most cases of prolactinomas medical treatment is effective ${ }^{2,3}$. Conversely, treatment of choice for non-secreting pituitary adenomas is mainly surgical ${ }^{4}$. The differential diagnosis is sometimes difficult as biochemical and classic imaging methods cannot differentiate accurately between these two conditions ${ }^{26,27}$. The basal prolactin levels may distinguish prolactinomas from nonsecreting adenomas only when they are very high. The 


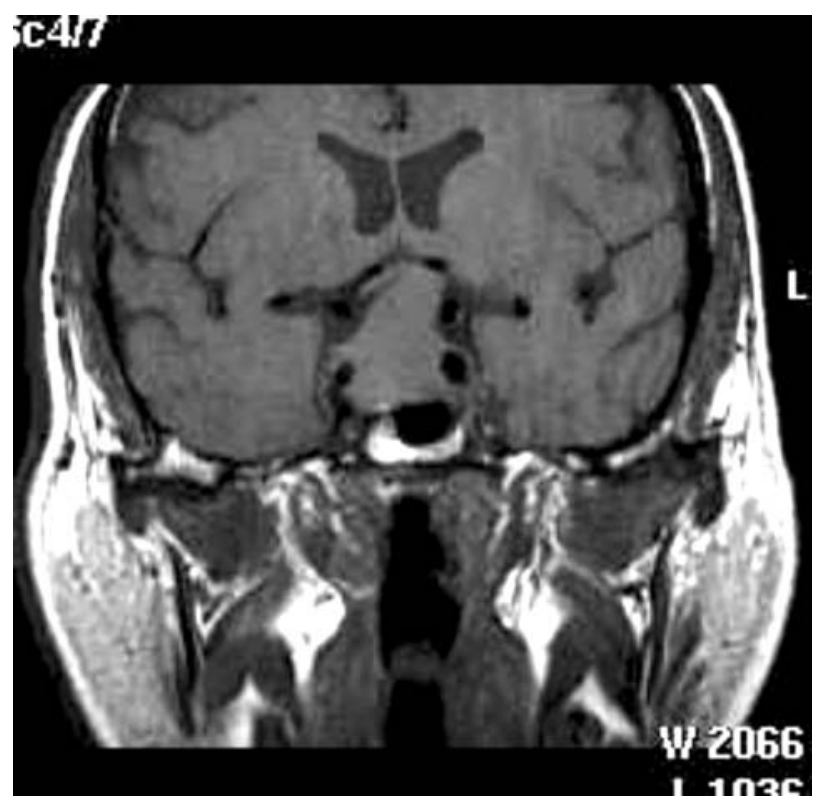

A
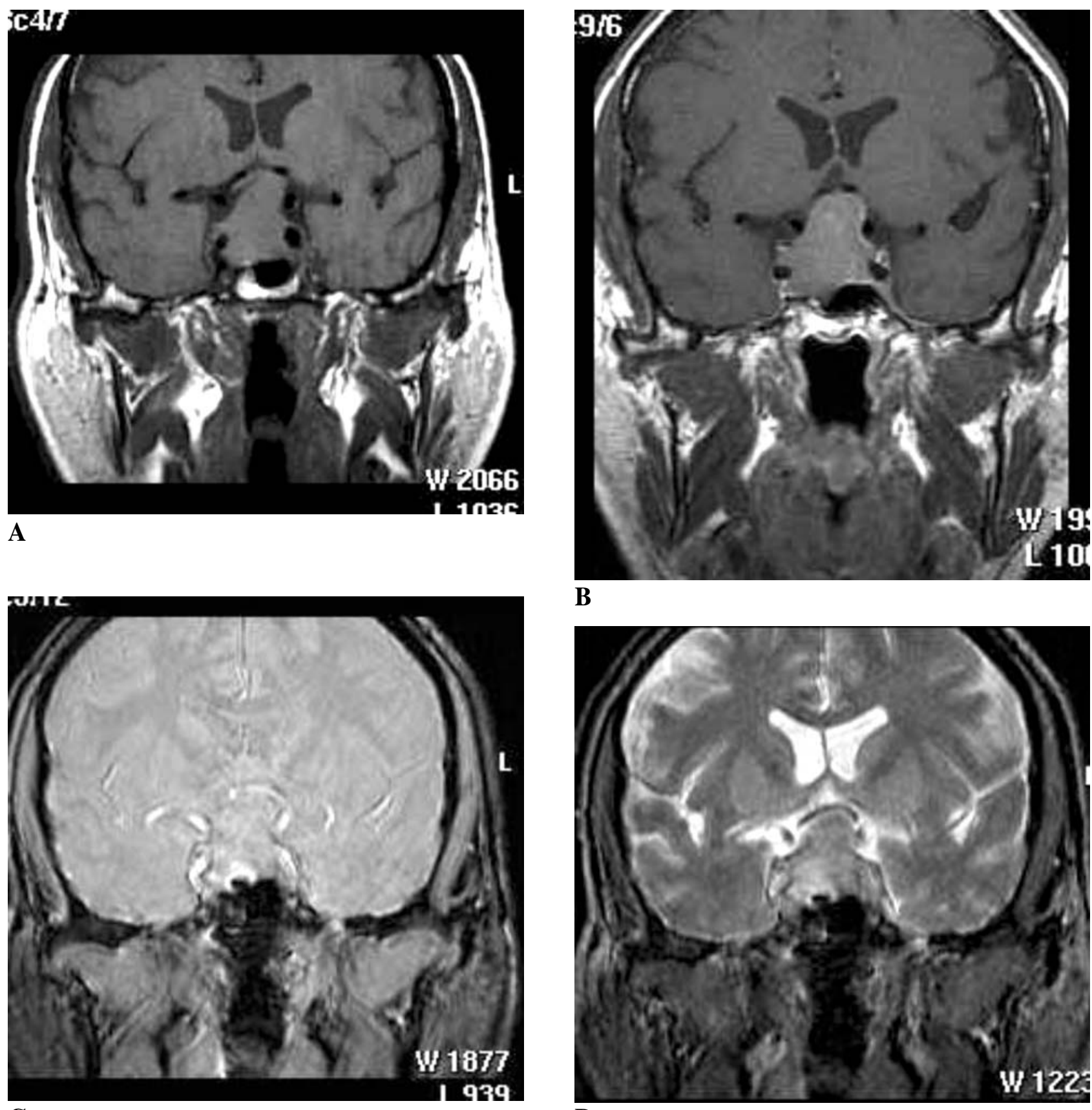

B

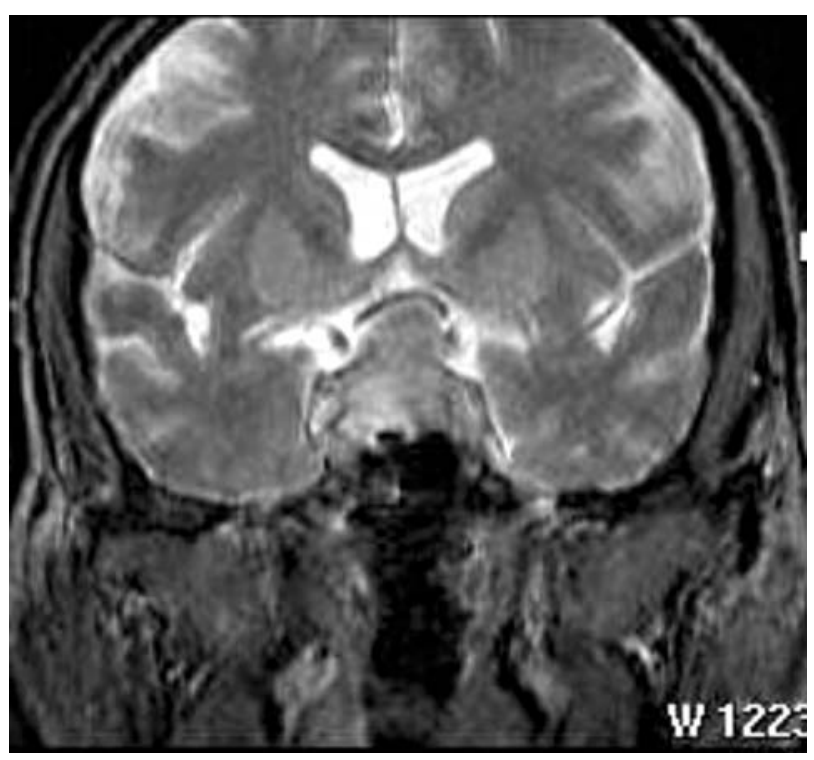

D

Figure 1.50 year-old men with non-secreting adenoma of the pituitary gland: A) spin echo- T1 weighted plain coronal scan shows a mass of intermediate signal intensity extending from the sella turcica up to the level of the optic chiasm; B) after intravenous contrast injection (GdDTPA), the lesion shows a heterogeneous enhancement; C) proton density coronal scan before; and D) after the application of the magnetization transfer prepulse, the mass exhibits a lower signal in (D) suggesting the presence of macromolecules.

stimulation of prolactin with TRH might help in the differential diagnosis but often atypical responses occur.

The RER is more prominent in secreting pituitary adenoma cells and, therefore, capable of more effect affecting $\mathrm{MTR}^{6,28}$. Thus, differences in MTR may exist between secreting and non-secreting adenomas. Recently it was shown that the MTR of prolactin-secreting tumors was significantly higher compared to normal pituitary of age and sex matched controls. 
Moreover, the MTR values of non-secreting adenomas were lower compared to those of normal pituitary of age and sex matched controls ${ }^{7}$. These data suggest that the use of this novel technique might be of value in the differential diagnosis of hyperprolactinemia.

This technique was also used for the post-operative assessment of growth hormone-secreting adenom$a^{6}$. In two patients presented with typical signs and symptoms of acromegaly, a complete endocrine investigation confirmed the diagnosis. The MR examination of the pituitary gland demonstrated a rightsided macroadenoma in the first patient and a leftsided macroadenoma in the second. The MR protocol consisted of spin-echo, T1 weighted, plain and contrast enhanced, sagittal and coronal scans. Trans-sphenoidal surgical procedure was the only treatment that the patients received. Post-operatively there was no suppression of GH during an OGTT and the serum IGF-I remained high. These results were indicative of persisting secretory activity suggestive of residual adenoma $^{29}$. A postoperative MR, using the classic protocol, did not show any sign of residual adenoma. Additionally, the MTR was measured on the right and left side of the gland. A 3D gradient echo sequence (32/8/6 repetition time/echo time/flip angle) was used to obtain concurrently coronal scans without and with magnetization transfer. In the first patient the MTR of the right side of the pituitary gland was considerably higher than the MTR of the left side (58\% vs $48.9 \%$ ). In the second patient the MTR of the left side was higher than the MTR of the right side (58.6\% vs $46 \%$ ). The higher MTRs on the one side of the gland may suggest persistence of secretory adenoma cells, which is in accordance with the endocrine tests.

These data suggest that the magnetization transfer technique may be used as an additional tool for the postoperative assessment and follow-up of patients with pituitary adenomas, especially when classic MR protocol does not show any sign of residual adenoma.

\section{FUTURE PROSPECTS}

Magnetization transfer imaging of the pituitary gland might be interesting in the investigation of pituitary insufficiency. Moreover, this technique may, in the future be used as an additional tool in the study of pituitary adenomas before and after treatment. Finally, it might be useful for the evaluation of other pituitary gland disorders such as precocious puberty.

\section{REFERENCES}

1. Sakurai K, Fujita N, Harada K, Kim SW, Nakanishi K, Kozuka T, 1992 Magnetic susceptibility artifact in spinecho MR imaging of the pituitary gland. AJNR Am J Neuroradiol 13: 1301-1308.

2. Molitch ME, Elton RL, Blackwell RE, et al, 1985 Bromocriptine as primary therapy for prolactin-secreting macroadenomas: Results of a prospective multicenter study. J Clin Endocrinol Metab 60: 698-705.

3. Thorner MO, McNeilly AS, Hagan C, Besser GM, 1974 Long-term treatment of galactorrhea and hypogonadism and bromocriptine. Br Med J 2: 419-422.

4. Wilson CB, 1990 Role of surgery in the management of pituitary tumors. Neurosurgl Clin N Am 1: 139-159.

5. Argyropoulou MI, Kiortsis DN, Metafratzi Z, Efremidis SC, 2000 Magnetization transfer imaging of the normal adenohypophysis: the effect of sex and age. Neuroradiology 43: 305-308.

6. Kiortsis DN, Argyropoulou MI, Bitsis S, Tsatsoulis A Efremidis S, 2000 Magnetization transfer technique: a new diagnostic tool for the postoperative assessment of pituitary adenomas. Clin Endocrinol 53: 399-400.

7. Kiortsis DN, Argyropoulou MI, Efremidis SC, Tsatsoulis A, 2001 Hyperprolactinemia induced by a non-secreting pituitary adenoma: Differential diagnosis with the magnetization transfer MRI technique. Clin Endocrinol 55: 423-426.

8. Grossman RI, Gomori JM, Ramer KN, Lexa FJ, Schnall MD, 1994 Magnetization transfer: Theory and clinical applications in neuroradiology. Radiographics 14: 279290.

9. Mehta RC, Pike GB, Enzmann DR, 1995 Magnetization transfer MR of the normal adult brain. AJNR Am J Neuroradiol 16: 2085-2091.

10. Okumura A, Kuwata K, Takenaka K, et al, 1998 Pulsed off-resonance magnetization transfer for brain tumor in patients. Neurol Res 20: 313-319.

11. Kurki T, Lundbom N, Komu M, Kormano M, 1996 Tissue characterization of intracranial tumors by magnetization transfer and spin-lattice relaxation parameters in vivo. J Magn Reson Imaging 6: 573-579.

12. Finelli DA, Reed DR, 1998 Flip angle dependence of experimentally determined $\mathrm{T} 1_{\text {sat }}$ and apparent magnetization transfer rate constants. JMRI 8: 548-553.

13. Holder CA, Elster AD, 1997 Magnetization transfer imaging of the pituitary: Further insights into the nature of the posterior "bright spot". J Comput Assist Tomogr 21: 171-174.

14. Vavasour IM, Whittall KP, MacKay AL, Li DKB, Vorobeychik G, Paty DW, 1998 A comparison between magnetization transfer ratios and myelin water percentages in normals and multiple sclerosis patients. Magn Reson Med 40: 763-768.

15. Wolff SD, Balaban RS, 1994 Magnetization transfer im- 
aging: Practical aspects and clinical applications. Radiology 192: 593-599.

16. Hajnal JV, Baudouin CJ, Oatridge A, Young IR, Bydder GM, 1992 Design and implementation of magnetization transfer pulsed sequences for clinical use. J Comput Assist Tomogr 16: 7-18.

17. Lundbom N, 1992 Determination of magnetization transfer contrast in tissue: an MR imaging study of brain tumors. AJR Am J Roentgenol 159: 1279-1285.

18. Van Waesberghe JHT, Castelijns JA, Scheltens P, et al, 1997 Comparison of four potential MR parameters for severe tissue destruction in multiple sclerosis lesions. Magn Reson Imaging 15: 155-162.

19. Koenig SH, Brown RD, 1991 Field-cycling relaxometry of protein solutions and tissue: implications for MRI. Prog NMR Spectrosc 22: 487-567.

20. Lodish H, Baltimore D, Berk A, Zipursky SL, Matsudaira P, Darnell J 1995 Cell organization, subcellular structure, and cell division In: Lodish H, Baltimore D, Berk A, Zipursky SL, Matsudaira P, Darnell J, (eds) Molecular cell biology $3^{\text {rd }}$ ed., Scientific American Books, New York; pp, 141-188.

21. Lehninger AL 1975 Biochemical aspects of hormone action In: Lehninger AL, (ed) Biochemistry $2^{\text {nd }}$ ed., Worth Publishers, New York; pp, 807-828.

22. Wolpert SM, Osborne M, Anderson M, Runge VM, 1988 The bright pituitary gland-A normal MR appearance in infancy. AJNR Am J Neuroradiol 9: 1-3.

23. Horvath E, Kovacs K 1995 Anatomy and histology of the normal and abnormal pituitary gland In: DeGroot LJ, (ed) Endocrinology $3^{\text {rd }}$ ed., WB Saunders, Philadelphia; pp, 160-177.

24. Simpkins JW, Estes KS 1984 Role of monoaminergic neurons in the age-related alternations in anterior pituitary secretion In: Nemeroff CB, Duun AJ, (eds) Peptides, Hormones and Behavior. New York; pp, 823-863.

25. Vermeulen A, Kaufman JM, 1992 Role of the hypothalamo-pituitary function in the hypoandrogenism of healthy aging. J Clin Endocrinol Metab 75: 704-705.

26. Klijn JGM, Lamberts SWJ, DeJong FH, Birkenhager JC, 1981 The value of the thyrotropin-releasing hormone test in patients with prolactin-secreting pituitary tumors and suprasellar non-pituitary tumors. Fertil Steril 35: 155-161.

27. Ferrari C, Rampini P, Benco R, Caldara R, Scarduelli C, Crosignani PG, 1982 Functional characterization of hypothalamic hyperprolactinemia. J Clin Endocrinol Metab 55: 897-901.

28. Horvath E, Kovacs K 1995 Anatomy and histology of the normal and abnormal pituitary gland In: Endocrinology, DeGroot LJ (ed) WB Saunders, Philadelphia; p, 167.

29. Melmed S, Jackson I, Kleinberg D, Klibanski A, 1998 Current treatment guidelines for acromegaly. J Clin Endocrinol Metab 83: 2646-2652. 